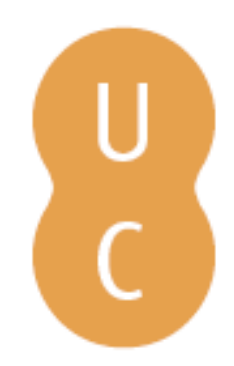

\title{
nombalina
}

\section{Rússia e União Europeia: dois gigantes e um continente}

Autor(es): $\quad$ Fernandes, Sandra Dias

Publicado por: Imprensa da Universidade de Coimbra

URL

persistente:

URI:http://hdl.handle.net/10316.2/31913

DOI:

DOI:http://dx.doi.org/10.14195/978-989-26-0712-2_7

Accessed : $\quad$ 26-Apr-2023 09:40:08

A navegação consulta e descarregamento dos títulos inseridos nas Bibliotecas Digitais UC Digitalis, UC Pombalina e UC Impactum, pressupõem a aceitação plena e sem reservas dos Termos e Condições de Uso destas Bibliotecas Digitais, disponíveis em https://digitalis.uc.pt/pt-pt/termos.

Conforme exposto nos referidos Termos e Condições de Uso, o descarregamento de títulos de acesso restrito requer uma licença válida de autorização devendo o utilizador aceder ao(s) documento(s) a partir de um endereço de IP da instituição detentora da supramencionada licença.

Ao utilizador é apenas permitido o descarregamento para uso pessoal, pelo que o emprego do(s) título(s) descarregado(s) para outro fim, designadamente comercial, carece de autorização do respetivo autor ou editor da obra.

Na medida em que todas as obras da UC Digitalis se encontram protegidas pelo Código do Direito de Autor e Direitos Conexos e demais legislação aplicável, toda a cópia, parcial ou total, deste documento, nos casos em que é legalmente admitida, deverá conter ou fazer-se acompanhar por este aviso.

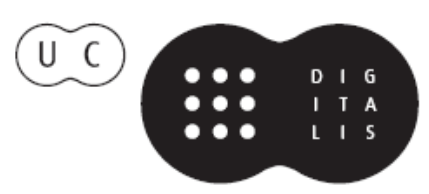


IMPRENSA DA

UNIVERSIDADE

DE COIMBRA

COIMBRA

UNIVERSITY

PRESS

\section{A POLÍTICA EXTERNA \\ RUSSA NO ESPAÇO \\ EURO-ATLÂNTICO}

$\therefore:$

\section{Dinâmicas de cooperaçấo e}

competiçẫo num espaço alargado

PÁTRICIA DAEHNHARDT

MARIA RAQUEL FREIRE

Coordenadoras 
(Página deixada propositadamente em branco) 


\section{CA P Í T UL O 7 \\ RÚ S S I A U N I ÃO EUROPEIA : \\ DOIS GIGANTES E UM CONTINENTE}

Sandra Dias Fernandes

Russia is an inalienable and organic part of Greater Europe and European civilization. Our citizens think of themselves as Europeans. We are by no means indifferent to developments in united Europe. (...) That is why Russia proposes moving toward the creation of a common economic and human space from the Atlantic to the Pacific Ocean - a community referred by Russian experts to as 'the Union of Europe' (Putin, 2012).

I will repeat what I said two years ago: the EU wants to be Russia's partner in its modernisation. We are indeed Strategic Partners. In many ways we are strongly interdependent. In a spirit of mutual benefit we can only win by deepening our cooperation even further (Van Rompuy, 2011).

\section{Introdução}

As relações entre a Rússia e a União Europeia (UE) são um elemento fundamental para as perspetivas de estabilidade na Europa. A forma como estes dois atores interagem tem um elevado impacto estratégico, sendo fundamental para a resolução dos desafios que se colocam à Europa. Desde o fim da Guerra Fria, a UE e a Federação Russa desenvolveram um quadro institucional único de cooperação. A partir de 1997, a sua relação foi 
organizada no âmbito do Acordo de Parceria e Cooperação (APC). A partir desse marco, evoluções significativas alargaram e aprofundaram as suas relações numa gama ampla de domínios. Para enfrentar a evolução da relação e a necessidade de melhorar a sua dimensão estratégica, uma nova metodologia de cooperação surgiu em 2003. A interação foi então reorganizada em quatro "espaços comuns" de cooperação. ${ }^{58}$ Desde 2010, ambas as partes visam desenvolver o que tem sido rotulado como uma "Parceria para a Modernização".

No entanto, apesar da aproximação vivida entre os dois maiores vizinhos europeus, o relacionamento tem sido desafiado por crescentes tensões. Desde a reeleição do Vladimir Putin em 2004 à presidência da Federação, a relação com Bruxelas tem sido marcada por dificuldades recorrentes. Foi notável o surgimento de duas características paradoxais. Por um lado, o método e os domínios de cooperação evoluiram postivamente, ao passo que, por outro lado, a qualidade da relação política deteriorou-se e os parceiros não têm sido capazes de formar uma verdadeira parceria estratégica. A guerra russo-georgiana de agosto de 2008 criou pressão adicional na já existente dificuldade de convergência política. Apesar de um diálogo abrangente e cooperativo, produzindo resultados concretos, principalmente nas áreas de economia e comércio, os resultados políticos não têm sido satisfatórios para nenhum dos parceiros. Isto é particularmente visível na demora em realizar uma parceria renovada (um novo acordo para substituir o APC, que deveria ter sido substituído em 2007).

Neste contexto paradoxal de crescente interdependência e tensões, este capítulo tem por objetivo compreender as relações que a UE e a Rússia têm vindo a desenvolver desde o fim da Guerra Fria. Procuramos abordar duas questões principais: qual é a natureza do diálogo político entre a UE e a Rússia, e qual é o potencial da relação na criação de soluções para desafios comuns. A nossa análise procura evidenciar os alcances e os obstáculos que caracterizam a relação UE-Rússia. Considerar esta questão é uma tarefa fundamental, no contexto da contínua reconstrução

58 Estes espaços são: (i) espaço económico comum, (ii) espaço comum de liberdade, segurança e justiça; (iii) espaço comum de cooperação no domínio da segurança externa, (iv) espaço comum de investigação, educação e cultura. 
da Europa, porque tem impacto na estabilidade da região. No processo de transição pós-Guerra Fria, o principal desafio tem sido a aproximação de antigos inimigos. Foram criados quadros originais de cooperação para enquadrar as relações com a Federação Russa mas esta última não está disposta a ser um país candidato à UE alargada.

A primeira parte do capítulo apresenta alguns traços principais das transformações que Bruxelas e Moscovo vivenciaram desde 1991 e que afetaram o seu relacionamento. O Kremlin teve de reposicionar a Rússia no palco europeu com uma nova identidade e um poder reduzido. A UE foi aprofundando e alargando o seu projeto de integração abarcando um número cada vez maior de países europeus, outrora aliados da antiga União das Repúblicas Socialistas Soviéticas (URSS), e delineando novas ambições no continente. A segunda parte do texto analisa o conteúdo da cooperação per se, ao descrever os alcances da relação. A terceira parte pondera os obstáculos inerentes ao diálogo russo-europeu.

\section{Uma era de transições: dois "novos" vizinhos com ambições re- novadas}

A UE e a Rússia tiveram de adaptar as suas políticas ao novo ambiente criado pelo fim de um ciclo histórico em 1991, a Guerra Fria. Os seus interesses e posicionamento internacional sofreram mudanças profundas, as quais ainda estão em curso. Esta parte do capítulo tem por objetivo expor as principais transições levadas a cabo por Moscovo e Bruxelas na medida em que tiveram impacto no seu relacionamento. Após a análise da vertente europeia da política externa russa, abordaremos a forma como a UE adaptou as suas políticas ao novo mapa europeu face ao vizinho russo.

\section{A Rússia: saindo das sombras}

A política externa russa evoluiu drasticamente desde os anos 1990, apresentando características complexas. Isso aconteceu por diferentes 
razões e teve impacto nas relações do país com terceiros, em particular na Europa. A Federação Russa é o principal Estado sucessor à URSS e teve um posicionamento atribulado na balança de poder global e regional. Vyacheslav Nikonov (2004), uma figura próxima de Putin, argumenta, em tom provocativo e eslovófilo, que "a Rússia é muito grande e muito russa". O autor refere-se à dificuldade da Federação em ser um país europeu "normal". Essa característica informa a sua política externa múltipla e desafiante, por ter tido que se adaptar a importantes mudanças internas e internacionais (Freire, 2012). O Kremlin aspirou a melhorar a sua capacidade externa de influência, e, com Putin, procurou exercer um contrapeso aos Estados Unidos da América (EUA) (Rowe and Torjesen, 2009; Borozna, 2007).

A questão de compreender a influência da Rússia em assuntos globais e europeus ganhou novo ímpeto com as duas presidências de Putin (2000-2008).59 Putin permaneceu em posição de poder após a eleição de Medvedev, em 2008, e a sua liderança marcou uma nova era para a Rússia que introduziu mudanças notáveis na relação com atores europeus, principalmente com a UE. Muitos consideram que a relação chegou a uma encruzilhada na medida em que não produziu a aproximação estratégica desejada. Na realidade, o ponto da situação no que diz respeito à aceitação das consequências do fim da Guerra Fria, durante os anos 1990 e o começo dos anos 2000, foi desafiado. Até então, a Federação Russa aceitava um status quo determinado pela sua posição mais fraca na balança de poder regional e global. Isso explica, em parte, a aproximação à UE, especialmente nas áreas económica e comercial, mas também, posteriormente, nos setores de segurança e defesa (ver abaixo). ${ }^{60}$ As relações entre a UE e a Rússia transformaram-se ao longo desse período, algo visível de forma mais marcante do lado russo.

A Rússia de Putin tornou-se uma parceira mais estável por ter gerado estabilidade interna nos níveis político e económico (Huskey, 2004, pp.

59 A terceira presidência, iniciada a 7 de maio de 2012, será analisada abaixo.

${ }^{60}$ A relação com a Organização do Tratato do Atlântico Norte (OTAN) levou à criação de um quadro institucionalizado de cooperação, baseado no Ato Fundador (1997). 
206-234; Shevtsova, 2004, pp. 141-195), apesar da exacerbação de tensões provocadas pela reafirmação internacional russa (principalmente durante o segundo mandato de Putin) e o problema da sua consolidação democrática (Sakwa, 2008, pp. 472-477). Bachkatov explica como Putin associou o poder político e económico a fim de atingir a meta de uma poderosa e respeitada Rússia (2007, pp. 137-150). Nesse período, de acordo com Nikonov, a Rússia falhou em juntar-se às instituições euro-atlânticas, e esse facto ocorreu na transição do século, quando a Rússia assumiu uma nova política e uma nova auto-identificação. Putin foi eleito nessa época, defendendo a multipolaridade, o pragmatismo e a aproximação ao ocidente (Nikonov, 2004).

Putin foi eleito em 2000 e reeleito duas vezes, em 2004 e em 2012. Foi o herdeiro direto da era Ieltsin mas tentou alterar o seu legado. Putin conseguiu transformar as incertezas da época do seu antecessor criando uma Rússia mais estável, tanto interna quanto externamente. Os resultados do período de Ieltsin podem ser resumidos nas seguintes características: uma democracia inacabada, um Estado federal desequilibrado e uma economia instável (Thumann, 2002). Zwang e Zwang sublinham a enormidade da obra que Ieltsin tinha para realizar, traduzida na implementação de uma democracia e de uma economia de mercado de modo a redefinir a identidade nacional e reencontrar um papel de grande potência no cenário internacional (2004, p. 165). Como consequência, o modelo político e económico ocidental que Ieltsin abraçou perdeu legitimidade pelas dificuldades de ajustamento que enfrentou. Esse facto levou os russos a desejar um homem forte que pudesse restaurar a "grandeza russa" (Thuman, 2002, pp. 170 e 208; Zwang and Zwang, 2004, p. 167). Quando questionado sobre a escolha de Putin como seu sucessor, Ieltsin respondeu que teve tempo de estudar o perfil de Putin e que uma das suas melhores qualidades residia no facto de não ser um maximalista, ao contrário de outros potenciais sucessores que defendiam modelos mais radicais para a transformação do país (Desai, 2006, pp. 83-84).

No compasso da abertura da Rússia para o ocidente, a Europa foi particularmente considerada (Herspring, 2003, pp. 225-256). O facto de a UE ser o maior parceiro comercial da Rússia contribui para explicar esta tendência. Por sua vez, a Rússia é o terceiro parceiro comercial mais importante da UE. 
A taxa de crescimento das exportações e importações aumentou significativamente, muito acima dos valores referentes ao comércio com os Estados Unidos da América (EUA) (Eurostat and Rosstat, 2007, pp. 198-199). De facto, existe uma forte interdependência económica e comercial entre os dois atores, mas também uma grande assimetria de desenvolvimento entre eles, que contribui de forma decisiva para o entendimento desta relação como fundamental. Putin enfatizou a importância dos esforços de aproximação com a Europa no seu discurso de 2001 no Encontro Federativo da Federação Russa, onde também sublinhou que o percurso da integração russa na Europa constitui uma das áreas-chave da sua política externa (Ivanov, 2002, p. 102). A questão do possível ingresso na UE permaneceu ambígua até ao segundo mandato de Putin, que corresponde a um novo momento de assertividade da Federação na cena europeia, como será exemplificado a seguir.

De facto, Ieltsin, em outubro de 1996, mencionara, publicamente, a possibilidade de a Rússia se tornar um Estado membro da UE. O primeiro ministro Viktor Chernomyrdin fez uma declaração similar durante uma visita a Bruxelas em junho de 1997 (Baranovsky, 2002, p. 176). Baranovsky, contudo, avalia a estratégia acima mencionada de duas maneiras distintas. Além da maior aproximação com a Europa, ele enfatiza a existência de dois posicionamentos opostos à entrada russa na UE devido às responsabilidades que emergiriam para o país (2002, pp. 33-34). Essa questão foi esclarecida durante o primeiro mandato do presidente Putin pelo primeiro ministro Kasyanov. Isso ocorreu em julho de 2001, quando o oficial destacou que a relação UE-Rússia era de linkage, e não de membership (Smith, 2002, p. 9).

A evolução do papel da Missão Permanente da Federação Russa junto da UE é um elemento adicional que aponta para a maior atenção que Moscovo tem devotado à sua relação com Bruxelas. Num curto período de tempo, correspondente ao final do primeiro mandato de Putin e ao começo do segundo, a missão cresceu cinco vezes. Isso correspondeu à expansão das competências comunitárias e a uma melhor consciência dos desenvolvimentos da UE. ${ }^{61}$ Pelos próprios padrões russos, a missão

61 Entrevista com um representante de um novo Estado membro em Bruxelas, a 13 de junho de 2007. 
tornou-se mais consistente, e alguns funcionários da UE consideram que o nível de especialização dos russos sobre o funcionamento da União é notável. Além disso, deve ser sublinhado que Moscovo prefere relações bilaterais com Estados membros em particular, de onde vai retirando dividendos, sendo certo, no entanto, que esta estratégia não é suficiente e que os russos devem lidar com a UE em questões que são decididas pelos 28 Estados membros em conjunto.

Durante o primeiro mandato de Putin, a política externa russa beneficiou do seu pragmatismo, criando laços mais fortes com o ocidente. No entanto, as habilidades pessoais de Putin reveleram os seus limites, e a aproximação começou a tornar-se mais difícil durante o seu segundo mandato. A política externa russa necessitava de iniciativas diplomáticas que poderiam ser mais construtivas e proativas quanto ao diálogo transatlântico para lograr o objetivo de contrabalançar a presença dos EUA nos quadros institucionais existentes. Exemplifica tal situação o facto de Putin procurar apoios na Europa enquanto não apoiando a intervenção norte-americana no Iraque, embora não tenha formulado críticas diretas a Washington, como o fizeram a França e a Alemanha (Coelho, 2004). Marcou posição, procurando no entanto manter o diálogo em aberto com o seu parceiro do outro lado do Atlântico. Além disso, as aptitudes de Putin no plano externo refletiam o endurecimento do seu regime, que havia começado no primeiro mandato e que continuou ao longo do segundo. Jack (2005) sintetiza as orientações da Rússia com Putin da seguinte forma:

"Putin tem feito muito para aumentar a credibilidade de seu país no exterior, provando ser um parceiro mais confiável e consistente do que Ieltsin. Ele foi ajudado pela ameaça externa do terrorismo e por uma procura crescente por fontes de energia abundantes da Rússia longe do instável Médio Oriente. Mas havia também um lado neo-imperial mais nacionalista que alertava para o facto de ele não estar simplesmente a transformar a Rússia num país ocidental." (Jack, 2005, pp. 5-6)

Sublinhamos acima que os dois primeiros mandatos do presidente Putin marcaram uma rutura com a era Ieltsin, uma vez que correspondem a 
uma dinâmica mais estável e cooperativa e a desempenhos económicos aprimorados. A posição da Federação Russa melhorou no cenário internacional e a sua política externa evoluiu em concordância. Desde então, um retorno da Rússia, devido ao grande crescimento económico e aumento de influência política que marcou a década pós-2000 até à crise financeira de 2008, tem sido observado na Europa e no mundo. Durante o período de Ieltsin, o PIB registou um crescimento positivo apenas em 1997, de 1,7\%, e em 1999 na ordem dos 6,4\%. Um desempenho negativo do PIB, uma produção industrial negativa e uma inflação enorme marcaram a década de noventa (Sakwa, 2008, p. 299; Vinhas de Souza, 2007 , p. 95). Vinhas de Souza (2007) apresenta uma análise detalhada da evolução macroeconómica russa de 1991 a 2008, nomeadamente o crescimento sustentado vivido desde 1999. O autor afirma que a Rússia se transformou num "país diferente" baseado nos efeitos das reformas económicas e estruturais e nos elevados preços da energia. No entanto, a crise global também afeta o curso de afirmação russa desde a crise financeira do verão de 1998. O ano de 2009 marcou o primeiro défice orçamental russo da década, causado nomeadamente pela descida do preço do petróleo (The Moscow Times, 2009).

A reeleição de Putin em março de 2012 deixa vislumbrar sérios desafios ao curso de reassertividade acima apresentado. Levantam-se também interrogações acerca das novas orientações da política externa russa. Certos analistas falam de um regresso "instável" e "hesitante" do líder russo (Emerson, 2012). O sinal porventura mais claro dado por Putin acerca do rumo que pretende dar à Federação russa encontra-se num artigo assinado por Putin e publicado num jornal russo, intitulado "Russia and the changing world" (Putin, 2012). O presidente russo reafirma a necessidade de uma Rússia forte para ser tratada em pé de igualdade e respeitada pelos outros países. No que concerne a Europa, Putin vislumbra a necessidade de unir esforços para enfrentar o aumento de poder da Ásia. No entanto, os eforços referidos dizem respeito sobretudo à área económica e à criação de um vasto mercado comum. Esta proposta é vista como solução para a crise da dívida soberana enfrentada pela UE. O tom do artigo é claro no sentido de afirmar a identade europeia do 
país e a vontade de cooperar com a UE para enfrentar desafios europeus e globais, sem no entanto deixar de sublinhar claramente o poder russo em também ajudar a União nos seus problemas e a necessidade de uma parceria conjunta para fazer face ao mundo global.

A Rússia tem vindo, de facto, a insistir cada vez mais na inelutabilidade da cooperação UE-Rússia para que os dois atores possam manter relevância internacional, procurando assim enaltecer a desejada igualdade que Moscovo procura no seu relacionamento com Bruxelas. Tsygankov (2012) esclarece a estratégia russa de política externa, a qual consiste em promover um mundo e uma governação multipolares através de uma aposta simultânea no relacionamento com instituições ocidentais e não ocidentais. Makarychev e Morozov (2011) explicam que a auto-perceção russa de grande potência faz com que Moscovo não se queira juntar às instituições transatlânticas mas tem, no entanto, a necessidade prática de cooperar com Bruxelas e Washington. A procura de uma parceria frutífera com a UE é, portanto, um traço duradouro dos desígnios russos num contexto mundial cada vez mais complexo.

Adicionalmente, surgiu recentemente uma dimensão interna com a qual a liderança russa renovada tem agora de lidar e cujos efeitos plenos estão, ainda, por revelar. Apesar do partido maioritário Rússia Unida e de Putin terem vencido as últimas eleições legislativas e presidenciais (2011 e 2012), surgiram movimentos de contestação internos inéditos. A crescente contestação interna ao resultado eleitoral e à reeleição de Putin contrariou a "verticalidade do poder" instaurada por Putin em 2001 e a sua figura de "czar" legítimo. Contrariando a ausência de oposição política dentro do sistema centralizador de Putin, vários grupos sociais incorparam, de forma inédita, a oposição ao regime de Putin e a vontade de participarem na vida política do país, defendendo, de acordo com um dos lemas principais das manifestações de dezembro de 2011, que Putin e o seu partido não representam os russos (Olimpieva, 2012). No âmbito das relações externas, o fim da apatia política da sociedade russa poderá trazer pressões nos campos em que Moscovo é regularmente criticado, nomeadamente o respeito pelo estado de direito e pelos direitos humanos. A título de exemplo, é notório o facto de existir, desde 2005, um 
diálogo sobre direitos humanos entre a UE e a Rússia e de ainda não ter sido possível agendar reuniões em território russo.

\section{A União Europeia: novas ambições a leste}

$\mathrm{O}$ alargamento institucional tem sido um marco fundamental nas transformações da UE no pós-Guerra Fria. Ao incluir os países da Europa central e oriental, que outrora faziam parte da antiga URSS, a União aproximou-se das fronteiras da Rússia e aumentou as suas ambições para leste. Os Conselhos Europeus de Copenhaga (1993) e Helsínquia (1999) marcaram este processo que se concretizou a 1 de maio de 2004 para oito destes países (juntamente com Chipre e Malta), passando a UE de 15 para 25 Estados membros. Em 2007, a Roménia e a Bulgária completaram o alargamento. ${ }^{62}$

Os novos Estados membros modificaram as perceções internas da UE acerca do seu papel no continente. A dicotomia entre antigos e novos membros é útil para caracterizar as diferentes visões. Isso foi particularmente visível na vontade de envolver a UE na resolução de conflitos na Europa, e na relação com a Rússia. Por um lado, alguns membros gostariam que Bruxelas se pautasse por princípios normativos, condicionando rigidamente a sua ação externa a valores comuns. Por outro lado, há Estados membros que valorizam uma postura mais realista e uma ação baseada na prossecução de interesses. Por exemplo, os três Estados Bálticos defendem uma voz unida face à Rússia e preferem lidar com o Kremlin ao nível de Bruxelas, e não bilateralmente. Países como a França, a Alemanha ou a Itália têm relações bilaterais privilegiadas com Moscovo. O exemplo porventura mais paradigmático desta dicotomia encontra-se nos assuntos energéticos. Desde 2006, acordos energéticos bilaterias foram assinados com a Federação Russa (Gazprom) para garantir fornecimentos de gás a esses países, em troca do acesso russo aos mercados nacionais. Face à ausência de uma política comum de energia, Moscovo tem vindo a usar

${ }^{62}$ Em julho de 2013, a Croácia elevou o número de Estados membros para 28. 
a sua vantagem energética, enquanto principal produtor e fornecedor, e aproveitado as divisões dentro da UE.

O quinto alargamento da UE, em maio de 2004, teve por consequência mais visível um novo mapa da Europa, tendo agora a UE uma fronteira comum com a Rússia e outros países da ex-URSS. A Rússia assumiu uma maior importância porque é o maior vizinho. Este facto explica a iniciativa política da UE, em março de 2003, intitulada Wider Europe Neighbourbood: a New Framework for Relations with our Eastern and Southern Neighbours, com o objetivo de desenvolver uma vizinhança de prosperidade e amizade. Genericamente, o objetivo desta política é partilhar os benefícios do alargamento com os Estados vizinhos, a fim de evitar a emergência de "novas linhas divisórias" no continente. Essa expressão retoma indiretamente a temática da "Europa fortaleza", i.e. a preocupação de a UE não ser um espaço fechado de estabilidade e desenvolvimento. Concretamente, Bruxelas criou, em 2004, uma Política Europeia de Vizinhança (PEV) direcionada para os países vizinhos a leste da Europa e na orla mediterrânica.

O facto de Bruxelas definir políticas especificamente delineadas para os países do antigo espaço soviético, no âmbito do seu conceito Wider Europe, permitiu a países como a Moldova, a Ucrânia ou a Geórgia desenvolver aspirações europeias e transatlânticas. No entanto, o crescente envolvimento de Bruxelas na região não é isento de tensões políticas com Moscovo. O Kremlin perceciona a Política de Vizinhança como uma iniciativa unilateral da UE, e como um desafio aos seus interesses. A relutância russa persistente em contribuir de forma positiva para a resolução dos "conflitos congelados" europeus ${ }^{63}$ enquadra-se nessa perceção. A agudização das tensões com Tbilisi levou ao deflagrar da guerra russo-georgiana de agosto de 2008. Desde então, a Rússia reconheceu, sem apoio internacional, a independência dos dois territórios separatistas da Geórgia, a Abcázia e a Ossétia do Sul. Consideramos que esta guerra sublinhou a necessidade de a UE conceber um novo modelo de relacionamento com Moscovo, nomeadamente em matéria de segurança e problemas de vizinhança.

63 A expressão refere-se aos conflitos territoriais oriundos da desintegração da antiga URSS. Existem disputas relativamente a regiões separatistas na Moldova, Geórgia, Arménia e Azerbaijão. 
No período pós-2008, a UE lançou uma nova iniciativa política com o intuito de melhorar a sua Política de Vizinhança a Leste, denominada Parceria Oriental. Esta nova política integra a PEV e foi promovida antes da crise georgiana, tendo em consideração a necessidade de desenvolver uma melhor oferta da UE, no seu flanco oriental. Esta política foi lançada oficialmente em maio de 2009, na cimeira de Praga (European Council, 2009). De forma semelhante à PEV, a Parceria Oriental visa promover a estabilidade nas fronteiras orientais externas da UE, sem oferecer garantias de adesão.

No entanto, a criação da Parceria Oriental reflete também a preocupação de alguns Estados membros em relação a Moscovo, nomeadamente no rescaldo da afirmação russa do seu poder na Geórgia em 2008. Esta intenção é visível no texto que promoveu esta iniciativa, emitido em conjunto pela Polónia e pela Suécia (Lapczynski, 2009). O texto reflete a vontade desses Estados membros de ter em consideração o desafio colocado pela Rússia aos países da vizinhança comum, para além do reconhecimento dos resultados limitados da PEV e da necessidade de a melhorar para ajudar os países parceiros na rota do desenvolvimento político, económico e social.

A criação da Parceria Oriental com seis países destaca, de facto, várias lacunas da PEV e a necessidade de abordar de forma mais consistente a transição na Arménia, Azerbaijão, Geórgia, Moldova, Ucrânia e, eventualmente, Bielorrússia. A tentativa de aprofundar a dimensão oriental da UE levanta a questão do impacto desta nova iniciativa num contexto de segurança tenso na Europa. A articulação entre a Parceria Oriental e as preocupações da UE com a Rússia é particularmente visível nas conclusões do Conselho Europeu de outubro de 2008 (Council of the European Union, 2008) porque, na sequência da guerra russo-georgiana ficou vísivel de que forma os países da Parceria Oriental constituem uma "vizinhança comum" problemática e partilhada entre a UE e a Rússia. Uma das conclusões do Conselho Europeu foi a criação de uma missão de monitorização da União na Geórgia, iniciada em outubro de 2008, o que aumentou a presença da UE na região. O maior envolvimento de Bruxelas nesta vizinhança tem, portanto, criado maiores dificuldades no relacionamento com Moscovo uma vez que se trata de uma área onde os russos têm interesses privilegiados. 


\section{O diálogo político e as áreas de cooperação entre a UE e a Rússia}

Do ponto de vista da UE, o propósito da relação com Moscovo foi, inicialmente, de evitar novas linhas divisórias na Europa, depois de ter superado as divisões bipolares da Guerra Fria. A aproximação de ex-inimigos emergiu, principalmente a partir de final dos anos noventa. Desde 1999, o relacionamento ganhou uma maior densidade estratégica. Concretamente, um quadro institucional de cooperação foi criado, composto por cinco elementos principais:

i) O Acordo de Parceria e Cooperação (APC) de 1997, que constitui a base institucional da relação UE-Rússia.

ii) Em 1999, dois documentos estratégicos foram adotados pelas duas partes (European Council, 1999; The Russian Federation, 1999).

iii) Desde 1998, ocorrem cimeiras bianuais.

iv) Órgaos de cooperação técnica, que preparam as cimeiras e implementam decisões.

v) Os programas de cooperação da UE são também instrumentos para o relacionamento criados por Bruxelas.

O APC é o alicerce para o surgimento do diálogo político, o qual é o primeiro resultado visível do acordo (Agreement on Partnership and Cooperation, 1997). Ele também substitui o anterior Tratado com a URSS de 1989, em conformidade com o artigo 112 do APC. É um acordo misto e abragente: foi concebido para gerir as relações económicas, comerciais e políticas por um período de dez anos renováveis.

O APC também permitiu dinamismo na evolução do relacionamento. O documento contém uma definição mínima do diálogo político mas a cooperação tem ido muito além daquilo que foi estipulado no APC, por vezes de forma genérica. Por exemplo, a segurança e a defesa eram apenas mencionadas geralmente através da referência ao desenvolvimento de um diálogo político que visa estabelecer novas formas de consulta e cooperação para promover a segurança internacional. Em 2000, esse dinamismo foi incorporado concretamente num documento ad hoc intitulado 
"Declaração conjunta sobre o diálogo e fortalecimento da cooperação em assuntos políticos e de segurança na Europa”, adotado em Paris. Em 1999, dois documentos estratégicos foram adotados por cada parte, acima mencionados. Hoje, ambos estão obsoletos pois foram substituídos por Planos de Ação adotados em 2005 (ver abaixo).

Quando Putin assumiu o poder em 2000 enquanto presidente, as relações UE-Rússia já beneficiavam de uma estrutura de cooperação institucionalizada e avançada em termos das áreas abrangidas. Esta relação tem evoluído desde então para uma maior maturidade, refletida no alargamento e aprofundamento da agenda de cooperação. Uma tendência definidora da relação é o facto dos objetivos económicos serem reforçados, dando assim a outras áreas uma prioridade secundária. A agenda de low politics (economia e comércio) tem sido mais desenvolvida do que a agenda de high politics (segurança e conflitos). ${ }^{64}$ Após as iniciativas tomadas nas cimeiras, a Comissão Europeia formulou o conceito de "Espaço Económico Europeu Comum”. A ideia comum de uma Europa unida economicamente, foi, assim, oficializada (Joint Statement, 2001).

$\mathrm{O}$ ano de 2003 representou um ponto de viragem no quadro da cooperação UE-Rússia, porque trouxe uma nova estrutura ad hoc de cooperação. Nesse ano, na cimeira de São Petersburgo, quatro espaços comuns foram criados (European Commission, 2003a):
1. um Espaço Económico Comum;
2. um Espaço Comum de Liberdade, Segurança e Justiça;
3. um Espaço Comum de Cooperação no domínio da Segurança Externa
4. um Espaço Comum de Investigação, Educação e Cultura.

Podemos interpretar a criação dos quatro espaços comuns como uma necessidade para enfrentar o alargamento a leste da União Europeia em 2004 (Directorate General External Relations, 2003). Em vésperas do alargamento, era necessário evitar que a Rússia se sentisse numa situação

${ }^{64}$ A secção anterior do presente capítulo contribuiu para explicar este facto uma vez que as ambições políticas externas de Bruxelas não têm colhido aceitação por parte de Moscovo. 
periférica, uma vez que não era um Estado membro nem um parceiro da política de vizinhança. Se excluirmos a responsabilidade política que está implícita para os países que pretendem ser candidatos à UE, nomeadamente através da incorporação de legislação da UE, o conceito de "quatro espaços comuns" pode ser visto como uma aproximação à UE (candidatura por proxi), porque os quatro espaços cobrem todos os campos das atividades da UE. Outra componente do quadro de cooperação institucionalizada é a referência a valores e princípios comuns contidos em todos os documentos e essenciais para uma "parceria UE-Rússia genuína” (European Council 2001, p. 13). O Conselho Europeu de Gotemburgo, em junho de 2001, definiu-os como sendo o estado de direito, a boa governação, o respeito pelos direitos humanos, incluindo os direitos das minorias, a promoção de boas relações de vizinhança, os princípios da economia de mercado e o desenvolvimento sustentável (European Commission, 2003b).

As áreas de cooperação abrangem vários setores, entre os quais: reforma da banca, contabilidade e auditoria; cultura; economia e comércio; energia; ambiente; ensino superior; direitos humanos e sociedade civil; liberdade, segurança e justiça; Kaliningrado; Cáucaso do Norte; Dimensão Nórdica; política regional; ciência e tecnologia; espaço; transporte; vistos e readmissão. Desde a adoção dos quatro espaços comuns, cinco relatórios de progresso foram aprovados publicamente pela Comissão Europeia para os anos de 2007 a 2011.65

No primeiro "espaço comum", foram criados "diálogos setoriais" de modo a concretizar a cooperação. Esses diálogos cobrem, nomeadamente, as seguintes áreas: transportes; política industrial e empresarial; diálogo regulamentar sobre os produtos industriais; espaço; sociedade da informação; agricultura, pesca, política macro-económica; serviços financeiros; energia; aquisições; meio ambiente; facilitação do comércio; direitos de propriedade intelectual; investimento; estatística; questões macroeconómicas e financeiras; cooperação inter-regional. A energia é

65 Os relatórios podem ser consultados na página internet do Serviço Europeu de Ação Externa, em http://eeas.europa.eu/russia/index_en.htm. 
um dos temas mais importantes nesta área de cooperação. Em 2000, as partes iniciaram um diálogo da energia que se materializa em três grupos temáticos: estratégias energéticas, previsões e cenários; evolução do mercado; e eficiência energética.

O segundo "espaço comum" de Liberdade, Segurança e Justiça é considerado uma área de crescente cooperação e as partes partilham o objetivo de isenção de vistos. Este domínio de cooperação visa combater o terrorismo, a migração ilegal e a criminalidade transfronteiras (que inclui o tráfico de seres humanos e drogas). Outra questão abordada nesta área de cooperação são os acordos fronteiriços. Em 2004, o alargamento da UE tem aumentado as fronteiras diretas da União com a Rússia, importando disputas fronteiriças de novos membros da UE. Concretamente, esta situação afetou os três Estados Bálticos que não tinham o reconhecimento oficial das fronteiras estabelecidas com Moscovo. O contra-terrorismo também está incluído no terceiro espaço comum de cooperação (segurança externa) mas é mais consistentemente abordado neste domínio de cooperação.

O terceiro "espaço comum" de cooperação inclui, por sua vez, a discussão de todas as questões de segurança internacional e cooperação em matéria de defesa e constitui a menos avançada das áreas de cooperação. A cooperação abrange exercícios militares virtuais, encontros entre peritos e a participação russa numa missão liderada pela UE (a missão EUFOR Chad/CAR, de 2008 a 2009). Existe também um diálogo entre Bruxelas e Moscovo na área de não-proliferação de armas de destruição em grande escala.

O quarto "espaço comum" de Investigação, Educação e Cultura, visa abranger "a cooperação entre instituições e pessoas que trabalham sobre os mesmos desafios comuns, um melhor conhecimento da história e culturas divergentes e maior contato entre as pessoas, particularmente as mais jovens" (European Commission, 2007, p. 8). Duas características principais surgem da análise dos quatro "espaços comuns" de cooperação. Em primeiro lugar, a cooperação evoluiu de forma desequilibrada em termos de atenção dedicada a cada área de cooperação. A cooperação económica e comercial tem sido favorecida em comparação com as outras áreas, não obstante o facto de elas terem também progedido. 
A cooperação comercial pode ser resumida na vontade de desenvolver uma área de livre comércio com a Rússia. Isso dependia também da adesão da Rússia à Organização Mundial do Comércio (OMC), que tem sido difícil de alcançar, e se concretizou em agosto de 2012. Em segundo lugar, todas as áreas de cooperação foram ampliadas e aprofundadas, nomeadamente após a nova metodologia de cooperação aprovada em São Petersburgo. Isto é particularmente visível no quarto espaço comum, que era quase inexistente enquanto área de cooperação antes de 2006.

O alcance da relação desde a entrada em vigor do APC em 1997 tem sido positivo em termos de criação institucional e da prática de um diálogo político. A relação é, portanto, marcada pela continuidade nas decisões tomadas e pragmatismo na prioridade dada às questões económicas. Alguma confiança política também emergiu do quadro de cooperação. A partir de 2000 o diálogo político expande-se com base na discussão de questões económicas às quais são adicionadas, de forma particular, questões de high politics na ordem do dia. Isso representou um aprofundamento e alargamento da agenda e também veio intensificar o nível de responsabilidade na relação. Neste curso de aprofundamento e alargamento da relação, tensões e dificuldades foram surgindo entre os parceiros.

\section{Dificuldades in crescendu na relação UE-Rússia}

A relação UE-Rússia revela um acervo significativo oriundo de uma relação de cooperação abrangente. A criação de canais de comunicação é certamente um dos maiores valores acrescentados da relação (diálogo político). No entanto, os problemas a enfrentar têm sido um desafio, no curto prazo, à construção desta relação sensível. Os dois atores embarcaram no processo de criação de alguma confiança política, inexistente no desfecho da Guerra Fria, tornando-se uma relação estratégica de longo prazo. No entanto, apesar dos resultados e das promessas do quadro de cooperação institucional UE-Rússia, a situação evoluiu de forma menos satisfatória para ambas as partes. O segundo mandato do presidente Putin (2004-2008) correspondeu a uma mudança na perceção da Rússia da sua 
posição em assuntos europeus, mas também a uma mudança de atitude da UE alargada em relação a Moscovo. Bruxelas tornou-se mais exigente e mais observadora dos assuntos internos russos, em particular no que concerne o funcionamento do seu regime político. Além do mais, esta atenção redobrada prendeu-se também com o processo de inclusão de novos Estados membros na UE com memórias históricas difíceis em relação à Rússia.

O resultado é uma relação difícil com mais críticas mútuas, materializada na dificuldade em negociar um período pós-APC depois de 2007. Esta situação reflete a dificuldade de avançar para uma verdadeira parceria estratégica. Ambas as partes também manifestaram grandes expetativas a nível retórico, as quais não foram concretizadas ou apenas o foram parcialmente. É particularmente visível na questão dos valores e princípios comuns inerentes a todas as referidas áreas de cooperação porque surgiram sérias dificuldades na convergência real e na adoção de normas. O exemplo mais claro desta discrepância entre Bruxelas e Moscovo tem sido as dificuldades do diálogo iniciado em 2005 sobre direitos humanos em produzir resultados concretos. Durante o contexto eleitoral russo, entre o final de 2011 e o início de 2012, as críticas ao funcionamento e regularidade dos processos também ilustraram divergências na interpretação das normas democráticas. Antes do escrutínio de dezembro de 2011, a diplomacia europeia já manifestava inquietações acerca do pluralismo na Rússia devido à dificuldade de certos partidos em registarem-se (European Union, 2011).

No final do segundo mandato de Putin como presidente da Federação Russa em 2008, um clímax foi atingido nas relações UE-Rússia. Além do reconhecimento mais ou menos entusiasta das conquistas da relação, os observadores concordaram sobre a necessidade de elevar a relação para um nível mais funcional. Como Burghardt (2008) sublinhou, um "recomeço" era necessário tendo em conta as mudanças de ambos os lados, sugerindo o fecho de um ciclo nas relações UE-Rússia e a abertura de um novo caminho para um tipo diferenciado de relacionamento. Arbatova (2008) identificou o ano de 2007 como o momento em que ambas as partes tomaram um rumo diferente. $\mathrm{O}$ ponto alto dos desentendimentos foi materializado no limbo de dois anos (2006-2008) que a relação atravessou. As partes superaram este período quando iniciaram o processo 
de negociação de um novo acordo de cooperação para substituir o APC, em julho de 2008. O objetivo do novo acordo será de cooperar com base num documento que reflita a evolução dos interesses e avanços da relação.

No entanto, uma visão pragmática sobre as relações UE-Rússia e os seus resultados permite reconhecer o acervo da cooperação em curso e desdramatizar as fases tensas da relação. A expetativa de resultados visíveis em cada cimeira não se concretizou, mas a estrutura de cooperação demonstrou duas capacidades principais. Por um lado, um diálogo aberto com Moscovo (nomeadamente sobre o conteúdo da parceria em curso) manteve-se, apesar dos contextos difíceis. Mesmo durante o período de reflexão que a UE decidiu levar a cabo, entre setembro e novembro de 2008, para tomar uma posição face ao comportamento belicista russo na Geórgia, o diálogo russo-europeu não parou. Apenas foram suspensos alguns ciclos de negociações para um novo acordo de cooperação. Por outro lado, os níveis de interação mais técnicos têm conseguido resultados setoriais, sobretudo a partir da reformulação da cooperação no âmbito dos "quatro espaços comuns" acordados em São Petersburgo em 2003. O quadro de cooperação gerou uma rotinização que explica a ausência de recuos, apesar dos períodos de abrandamento, assim como explica o alargamento e aprofundamento da agenda de cooperação.

É possível observar uma discrepância entre, por um lado, os discursos russos que não são conciliatórios e a atitude da UE que critica o funcionamento democrático da Rússia, e, por outro lado, a dimensão pragmática da relação. A relação evoluiu e alcançou resultados de cooperação em cada um dos quatro espaços comuns, sem existir no entanto um acordo sobre todos os princípios da relação. A situação criada pode, portanto, parecer paradoxal. Uma das tensões mais visíveis nas relações UE-Rússia de hoje assenta, de facto, na ausência de partilha efetiva de valores e princípios comuns, que deveriam ser a base da parceria. Para Moscovo, o método de condicionalidade da UE (o qual consiste em vincular as suas relações com terceiros à observância de valores) não contribui para a obtenção de resultados construtivos. A insistência da UE no discurso normativo é contrariada pela afirmação, por parte do Kremlin, da especificidade 
cultural da Rússia e do seu direito a uma interpretação diferente do conceito de democracia, intitulada de "democracia soberana" por Putin. Conforme acima demonstrado, o autoritarismo de Putin tem vindo a ser posto em causa por movimentos internos de contestação significativos. Estes factos recentes deixam vislumbrar a necessidade do presidente rever a sua forma de exercício do poder, o que poderá, eventualmente, ter efeitos na agenda normativa com a UE.

A relação UE-Rússia organiza-se, hoje, em torno de uma "Parceria para a Modernização". A expressão foi cunhada em 2010 e remete para objetivos de cariz essencialmente económico, apesar da União persistir com um discurso de convergência normativa. Cada uma das partes procura promover assuntos para o topo da agenda. Se para os russos a criação de uma política de isenção de vistos surge como uma das prioridades, os europeus, por seu lado, anseiam por uma melhor cooperação nos domínios comercial e energético. A entrada da Rússia para a OMC em 2012 encerra quase duas décadas de negociações e abre novas perspetivas no âmbito do primeiro "espaço comum" de cooperação com a UE, no sentido de diminuição das barreiras comerciais e da liberalização das trocas.

\section{Conclusão: da necessidade de cooperar face às transformações globais}

Ao longo dos anos noventa deu-se uma aproximação institucional, de natureza política, entre a UE e a Rússia. A qualidade e a densidade desta aproximação foram mais notórias no final dos anos 1990. Existe um quadro único e institucionalizado de cooperação entre a UE e a Rússia que tem produzido resultados específicos, principalmente em domínios económicos. A cooperação tem-se, no entanto, alargado e aprofundado para além desta área. As questões de segurança são discutidas sistematicamente desde 2000 e outros campos, como educação e assuntos internos, também foram desenvolvidos. No entanto, a relação tem enfrentado limitações na obtenção de resultados concretos de cooperação, nomeadamente na feitura 
de um novo acordo de parceria, por um lado, e por outro, no domínio da segurança não se conseguiu avançar na definição de um quadro securitário que satisfaça os objetivos - não consensuais - de Bruxelas e Moscovo.

Estas limitações advêm de um conjunto de factores. Em primeiro lugar, existe um desequilíbrio entre os quatro principais domínios de cooperação, em favor da cooperação económica, o que torna difícil criar sinergias na agenda global de cooperação. Além da consideração de resultados cooperativos desiguais nos quatro "espaços comuns", as dificuldades em encontrar soluções aumentaram durante o segundo mandato de Putin, não tendo registado progressos significativos com Medvedev. A declaração pelo respeito de valores e princípios é a referência orientadora da relação a nível retórico mas tem sido cada vez mais desafiada por falta de cumprimento. Esta evolução agudizou as tensões que criam obstáculos à obtenção de resultados de cooperação.

A solução passaria, porventura, por uma atenção mais equilibrada a cada um dos quatro "espaços comuns" de São Petersburgo. Existe um entendimento generalizado segundo o qual as dificuldades de convergência podem ser superadas, a médio ou longo prazo, desde que os contatos entre as populações sejam intensificados. Isso poderia resolver os problemas de perceção mútua, ainda marcada por desconfianças históricas e uma certa desilusão em relação ao pós-Guerra Fria. Esta é a tarefa do "espaço comum" de Investigação, Educação e Cultura. O antigo primeiro ministro Kasyanov (2008) sublinhou que os cidadãos russos precisam de ter a oportunidade de comunicar com os cidadãos da UE, a fim de promover uma aproximação nos valores para além do interesse de Bruxelas nas negociações económicas.

A cooperação tem sido, portanto, fomentada entre a UE e a Rússia, mas ainda existe controvérsia na interpretação do valor acrescentado desta cooperação no contexto da política global e como uma ferramenta para resolver questões específicas. Aqui deve ser sublinhada a existência de pontos de vista opostos sobre as relações UE-Rússia. Alguns consideram que a relação alcançou pouco no tratamento das questões europeias e globais e, pelo contrário, outros valorizam os resultados das relações UE-Rússia. O reconhecimento do alcance do quadro de cooperação, em conjunto com os obstáculos inerentes, pode contribuir para reduzir o 
paradoxo que marca a relação UE-Rússia. Desde o fim da Guerra Fria, as partes deixaram de ser inimigas na cena europeia mas ainda não alcançaram a parceria desejável.

No início do século XXI, Emerson (2001, p. 14) identificava quais seriam os desafios para as relações UE-Rússia: "como poderemos desenhar estratégias de cooperação conjunta para a UE e a Rússia nas periferias que se sobrepõem e onde a Rússia tem sido, e continua a querer ser o principal ator?". Hoje, tornou-se claro que estes dois atores diferenciados precisam de encontrar formas de cooperação mais frutíferas para partilhar um continente que lhes é comum. Para Emerson (2001, p. 18), a ideia de Gorbachov de uma "casa comum europeia" deveria ser reabilitada para que a UE e a Rússia possam viver pacificamente. No contexto atual de gestão da crise global, despoletada pela crise financeira de 2008, e face à emergência de novas potências não europeias, existem apelos para a necessidade de reforçar a relação de Bruxelas com Moscovo para manter peso no sitema internacional. Os desafios à relação colocam-se hoje para além da partilha do continente europeu e atingiram, portanto, uma dimensão mais global.

Na sequência do anúncio da sua candidatura a um terceiro mandato presidencial em setembro de 2011, Putin revelou um ambicioso projeto, uma "União Eurasiática”, que visaria integrar todos os Estados pós-soviéticos, da Bielorrússia ao Tajiquistão, nos campos político e económico (Bryanski, 2011). Embora a sua concretização ainda careça de medidas concretas, a ideia de um projeto de integração regional liderado por Moscovo levanta preocupações sobre as novas orientações da política externa russa. Uma das principais questões diz respeito à articulação entre a União e as instituições já existentes e as relações cooperativas, nomeadamente com a UE (e a China). Paralelamente, a ideia de uma "União da Europa" para enfrentar uma perda de poder a nível global também emergiu dos círculos intelectuais russos (Karaganov et al., 2010) e é retomada por Putin. Esta "União" surgiria a partir de uma cooperação mais orientada para os resultados, condição tida como necessária para tornar a UE e a Rússia os terceiros maiores atores mundiais, atrás dos EUA e da China. Nesta perspetiva, sem um esforço conjunto para esse desígnio, o poder da Rússia e da UE diminuirá para ambas. 


\section{Bibliografia}

BACHKATOV, Nina - Les interactions entre pouvoir économique et politique en Russie. In Merlin, Aude, ed., Où va la Russie?. Bruxelles: Editions de 1'Université Libre, 2007. p. 137-152.

BARANOVSKY, Vladimir - Russia's Attitudes towards the EU: Political Aspects. Programme on the Northern Dimension of the CFSP, 2002.

BOROZNA, Angela - Russian Multilateralism since 1991. Comunicação apresentada na International Studies Association Annual Convention, Chicago, 2007.

BRYANSKI, Gleb - Russia's Putin says wants to build 'Eurasian Union'. Reuters, 3 outubro 2011. [Acedido a 2 de nov. de 2011]. Disponível na Internet: http://www.reuters.com/ article/2011/10/03/us-russia-putin-eurasian-idUSTRE7926ZD20111003.

BURGHARDT, Günther - Session II: The way ahead: prospects for EU-Russia relations. Conference on EU-Russia Relations: a Trouble Strategic Partnership? Brussels: Palais d'Egmont, 27 fevereiro 2008.

Council of the European Union - Javier Solana, EU High Representative for the CFSP, confirms the withdrawal of Russian forces from the zones adjacent to South Ossetia and Abkhazia. S332/08. Bruxelas, 10 outubro 2008.

DESAI, Padma - Conversations on Russia. Reform from Ieltsin to Putin. Oxford: Oxford University Press, 2006.

Directorate General External Relations - Overview. EU-Russia Summit. Roma, 6 novembro 2003. [Acedido a 10 de jan. de 2012]. Disponível na Internet: http://europa.eu.int/comm./ external_relations/russia/summit11_03/ip03_1496.htm.

EMERSON, Michael - Some Paradigms for the Evolving Map of Europe. CEPS Working Document 164, abril 2001.

EMERSON, Michael - Putin's faltering return. CEPS ENW. N. ${ }^{\circ}$ 78, 2012.

European Commission - Comunicado de imprensa. EU-Russia Summit. São Petersburgo, 31 maio 2003a. [Acedido a 15 de ago. de 2012]. Disponível na Internet: http://europa. eu.int/comm./external_relations/russia/sum05_03/ip03_768.htm.

European Commission - Paving the Way for a New Neighbourhood Instrument. COM(2003)393 final. Brussels, 1 julho 2003b. [Acedido a 21 de jan. de 2012]. Disponível na Internet: http://ec.europa.eu/world/enp/pdf/com03_393_en.pdf.

European Commission - The European Union and Russia: Close Neighbours, Global Players, Strategic Partners, 2007. [Acedido a 21 de jan. de 2012]. Disponível na Internet: http:// ec.europa.eu/external_relations/library/publications/russia_brochure07_en.pdf.

European Council - Joint Declaration of the Prague Eastern Partnership Summit. Prague, 7 maio 2009. [Acedido a 4 de out. de 2011]. Disponível na Internet: http://europa.eu/rapid/ pressReleasesAction.do?reference $=$ PRES/09/78\&format $=$ HTML\&aged $=0 \&$ language $=\mathrm{EN} \& \mathrm{~g}$ uiLanguage $=$ en.

European Council - Conclusions of the Presidency. SN 200/101VER 1. European Council of Göteborg, 15 e 16 junho 2001. [Acedido a 4 de out. de 2011]. Disponível na Internet: http://ec.europa.eu/governance/impact/background/docs/goteborg_concl_en.pdf.

European Union - Statement by the spokesperson of High Representative Catherine Ashton on party registration in Russia. A 244/11. Bruxelas, 22 junho 2011. [Acedido a 4 de out. de 2012]. Disponível na Internet: http://www.consilium.europa.eu/uedocs/cms_data/ docs/pressdata/FR/foraff/123022.pdf.

Eurostat and Rosstat - The European Union and Russia. Statistical Comparison 1995-2005. Eurostat Statistical Books and Rosstat, 2007. 
FREIRE, Maria Raquel - A Rússia de Putin - Vectores Estruturantes de Política Externa. Coimbra: Almedina, 2012.

HUSKEY, Eugene - A Liderança Política e a Luta entre o Centro e a Periferia: As Reformas Administrativas de Putin. In Brown, Archie e Shevtsova, Lilia, eds., Gorbachev, Ieltsin $\mathcal{E}$ Putin. A Liderança Política na Transição Russa. Editora Universidade de Brasília (translation from the Carnegie Endowment for International Peace, Washington, 2001), 2004. p. 197-234.

IVANOV, Igor S. - The New Russian Diplomacy. Washington, DC: The Nixon Center and Brookings Institution Press, 2002.

JACK, Andrew - Inside Putin's Russia. London: Granta Publications, 2005.

KARAGANOV, Sergei et. al. - Towards an 'Alliance of Europe'. Analytical Report by the Russian Group of the Valdai International Discussion Club'. St. Petersberg, Kizhi-Valaam, Moscow, 31 agosto - 7 setembro 2010. [Acedido a 25 de fev. de 2011]. Disponível na Internet: http://karaganov.ru/content/images/uploaded/4b4ec04c237e760f0808556999573c53.pdf.

KASYANOV, Mikhail - Russia after the elections: what potential for common values?. Study day of the EPP-ED Group on Russia. Brussels: European Parliament, 15 maio 2008.

LAPCZYNSKI, Marcin - The European Union's Eastern Partnership: Changes and Perspectives. Caucasian Review of International Affairs. Vol. 2, n. 3 (2009), p. 143-155. [Acedido a 20 de set. de 2009]. Disponível na Internet: http://www.cria-online.org/7_3.html.

MAKARYCHEV, Andrei e MOROZOV, Viatcheslav - Multilateralism, Multipolarity, and Beyond: A Menu of Russia's Policy Strategies. Global Governance. Vol. 17, n. 3 (2011), p. 353-373.

Moscow Times, The - Kudrin dwells on budget deficit. 25 novembro 2009.

NIKONOV, Vyacheslav - Russia and European Community: politics and economics. Russian Summer Session: The Europe/Russia Relations in the new enlarged Europe. Moscow: International University of Moscow, 15-23 julho 2004.

OlimpIEVA, Evgenia - Russia's Protest Movement: A View from a Young Participant. Russian Analytical Digest. N. 108 (2012), p. 10-13.

PUTIN, Vladimir - Russia and the changing world. Artigo do prmeiro ministro Vladimir Putin, Moskovskiye Novosti, 27 fevereiro 2012. [Acedido a 28 de fev. de 2012]. Disponível na Internet: http://premier.gov.ru/eng/events/news/18252/.

ROWE, Elana Wilson e TORJESEN, Stina, eds. - The Multilateral Dimension in Russian Foreign Policy. London and New York: Routledge, 2009.

SAKWA, Richard - Russian Politics and Society (fourth edition). Oxon and New York: Routledge, 2008.

SMITH, Mark A. - Contemporary Russian Perceptions of Euro-Atlanticism. Conflict Studies Research Centre, fevereiro 2002.

SOUZA, Luís Vinhais de - A Different Country. Russia's Economic Resurgence Brussels: CEPS, 2007.

The Russian Federation - The Russian Federation Middle Term Strategy Towards the European Union (2000-2010), 1999. [Acedido a 7 de mai. de 2004]. Disponível na Internet: http:// www.delrus.ec.europa.eu/en/p_245.htm.

THUMANN, Michael - La puissance russe. Un puzzle à reconstituer? Paris: Alvik Éditions, 2002.

TSYGANKOV, Andrei P. - Russia and Global Governance in the Post-Western World. Russian Analytical Digest. N. ${ }^{\circ} 114$ (2012), p. 2-4.

VAN ROMPUY, Herman - Comentários de Herman Van Rompuy, President of the European Council, following the $28^{\text {th }}$ EU-Russia Summit. EUCO 162/11 PRESSE 500 PR PCE 121. Bruxelas, 15 dezembro 2011. [Acedido a 20 de fev. de 2012]. Disponível na Internet: http://www.consilium.europa.eu/uedocs/cms_data/docs/pressdata/en/ec/126952.pdf.

ZWANG, Annie e ZWANG, Philippe - De la Russie de Catberine II à la Russie d'aujourd'bui. 1762-début du XXIe siècle. Paris: Ellipses, 2004. 
(Página deixada propositadamente em branco) 
